\title{
New Attempt of Curriculum Reform: A Case Study of Physics STEAM Curriculum in a Senior High School
}

\author{
Yuxuan Yang1, Yan Fan ${ }^{1}$, Hui Lu², Hong Yuan ${ }^{1}$, and Li Xie ${ }^{1, *}$ \\ ${ }^{1}$ School of Physics and Optoelectronic Engineering, Yangtze University, Jingzhou 434023, China \\ 2 School of Petroleum Engineering, Yangtze University, Jingzhou 434023, China \\ *Corresponding Author: shirlyxieli@yahoo.com
}

(Received: 10/13/2019; Accepted: 06/29/2020; Published: 09/30/2020)

DOI: https://doi.org/10.37906/real.2020.5

\begin{abstract}
The curriculum is the carrier of teaching activities and an important measure for cultivating national scientific and technological talents. STEAM education originated from the United States, as an interdisciplinary and integrated education mode to cultivate comprehensive talents in the future, aims at improving students' scientific and humanistic literacy, and emphasizes the cultivation of students' lifelong learning awareness, problem-solving ability, scientific inquiry ability and innovation ability. Therefore, designing a STEAM Curriculum with inquiry and engineering orientation has important guiding significance for China's basic education reform. This paper takes the "Manufacturing of Hydraulic Manipulator" as the project theme, and based on the 6E learning by design model, discusses the design of STEAM physics curriculum.
\end{abstract}

Keywords: STEAM Education; 6E Learning by Design Model; Physics Curriculum Design

\section{Introduction}

In the 21st century, with the rapid popularization of the Internet, emerging technologies such as artificial intelligence and big data have changed the way people work, live, learn and interact. Therefore, countries urgently need to cultivate new talents who can adapt to the rapid growth trend of information. Faced with such needs, our education should not be limited to the teaching of conventional cultural knowledge. Instead, it should cultivate the comprehensive ability of learners to use knowledge and skills to solve problems. While paying attention to their knowledge transfer and problem-solving development, it is necessary to focus on cultivating students' critical thinking and innovative spirit. Besides, as the knowledge and abilities required to solve technical problems become increasingly integrated and complex, the ability to apply interdisciplinary knowledge to solve complex problems becomes necessary (Bybee, 2013; Havic, 2009). However, the disciplinary egocentrism (Richter \& Paretti, 2009) in traditional education limits the students' innovative thinking and practical ability because they cannot accurately relate the various disciplines (Connor, Karmokar \& Whittington, 2015). Many reports have warned that school education often failed to prepare our students to solve real-world problems because of the disconnected knowledge acquired from individual school subjects (Bybee, 2013; Toulmin \& Groome, 2007; Honey, Pearson \& Schweingruber, 2014). Compared with traditional education, STEAM Education (Science, Technology, Engineering, Arts, Mathematics) proposed by the United States is organized by adding "who will do" and "why to do" in Arts (Yakman, 2010) to "what to do" and "how to do" in STEAM Education. STEAM education includes five levels of lifelong learning, comprehensive learning, multidisciplinary 
learning, subject learning, and specific content learning, emphasizing the integration of content between different disciplines to cultivate students' scientific literacy and humanistic qualities. And the connotation of STEAM education is not only to effectively cultivate students' abilities of logical thinking, problemsolving, innovation, cooperation, motivation, etc., but also to shape students into all-round people with the spirit of creation and innovation, and to support students to become future inventors and creators (Yakman, \& Lee, 2012).

At present, the world economy is amid deep adjustment and promoting growth has become the consensus of the international community. Li Keqiang, premier of the State Council of China, emphasized the concept of "Mass Innovation, Mass Entrepreneurship" in the government work report in 2015, and pointed out that to cultivate and grow new economic and social dynamics, it is necessary to accelerate the implementation of the innovation-driven development strategy, which reflects the country's demand for high-level talents, while the cultivation of high-level talents needs to match first-class education. The interdisciplinary approach of STEAM education combines the practical activities and spiritual connotations of the discipline, which is in line with the current training mode of compound innovative talents in China. However, there are still many shortcomings in the study of STEAM education in China. In most areas, STEAM education is limited to the level of labor technology or general technology courses in primary and secondary schools, for example, some primary and secondary schools include visual programming, robotics, and open-source hardware in information technology. And general technology courses to strengthen the cultivation of students' innovation and practical ability. However, lacking the development of STEAM education curriculums in other disciplines, and the overall lack of macrosystem planning and specific implementation programs.

\section{Purpose of the Study}

Based on foreign experience, based on the physics subject in high school, integrating other disciplines to design the STEAM curriculum is an attempt to transform STEAM education in the development of China's physics curriculum system.

The knowledge in the High School Physics Elective 2-2 textbook of Human Education Edition focuses on the application of technology, emphasizing the integration of physics and technology, which is very suitable for teaching using the STEAM education model. Therefore, this study takes "manufacturing of hydraulic manipulator" as the project activity theme to study the STEM curriculum design scheme based on "Hydraulic Transmission" in Chapter 3, Section 3 of the textbook. We hope to provide a reference for STEAM education for primary and middle school teachers in China.

Our research questions are given below:

(1) How to design the STEAM curriculum of "manufacturing of hydraulic manipulator"?

(2) How should the STEAM curriculum case on "manufacturing of hydraulic manipulator" be evaluated effectively to achieve teaching feedback?

(3) How is this curriculum case different from traditional curriculum teaching?

\section{Literature Review}

\subsection{The Necessity of STEM Curriculum Research}

Referring to the curriculum standards of primary and secondary schools developed by Australia, the United States, Canada, South Korea, and Finland, countries emphasize that primary and secondary school curriculum should break the boundaries of disciplines, strengthening interdisciplinary integration, and focusing on crosscutting concepts and disciplinary core ideas (Anderson, Sarah, Covitt, Edwards \& Brian, 
2018). The integrated development of students' abilities has become one of the trends of international curriculum standards.

China's newly promulgated Standards for Physics Curriculum in Senior High Schools (2017 edition) emphasizes that the physics curriculum in senior high schools should cultivate students' core literacy (Hill, 2013) in terms of physical concept, scientific thinking (Erman, Wasis, Susantini \& Azizah, 2018), scientific inquiry (Angranini \& Sani, 2016), scientific attitudes and responsibilities, laying a good foundation for students' lifelong learning and adapting to society. The basic concept of Standards for Chemistry Curriculum in Senior High Schools (2017 edition) also mentioned: Chemistry teaching should start from students' experience, advocate creating real problem situations to carry out teaching and pay attention to the connection among reaction chemistry, technology, engineering and society in teaching content, to improve students' ability to analyze and solve problems in real problem situations, to develop students' discipline core literacy. Also, the Compulsory Primary School Curriculum Standards (2017 Edition) adds "Technology and Engineering" content to the science curriculum, and advocates the association and interaction with mathematics, Chinese, and comprehensive practice activities. It can be seen that these curriculum standard programs all emphasize the effective connection of different segments and the integration of curriculum objectives of different disciplines, reflecting the integration of steam education ideas and the new direction of continuous development in the level of curriculum standards in China. According to J.A. Vasquez and other scholars, students can only acquire the skills of a single discipline when they study a single discipline. With the integration of disciplines, the degree of interdisciplinary connection increases, and the requirements for learners are higher. The more you learn, the more you can learn. Interdisciplinary learning enables students to not only grasp the intrinsic links between concepts but also to transfer knowledge to real problems to form solutions. STEAM education not only requires students to integrate fragmented knowledge, learn in a multi-perspective and multi-dimensional way, cultivate students' rational thinking logic, scientific inquiry ability and cooperation and communication ability, and develop students' ability to solve problems comprehensively and innovate.

\subsection{E Learning by Design Model}

To practice the interdisciplinary concept of the STEAM education, the development and design of STEAM curriculum is the key. As the initiator and main promoter of STEM education, the American education community has done a lot of research and practice. For example, to promote STEAM education practice, the United States has launched several related teacher training programs and developed a wealth of teacher training resources. Five universities in the United States launched the UTe-ach program in the fall of 2014. The program focuses on the cultivation of undergraduate teacher qualifications, forming the current excellent teacher program of Science education, and is committed to cultivating more high-quality science and technology education in the future Division (USNews, 2014). And influential education, policy, and business groups in the United States have also made some recommendations and reports on the promotion and development of STEAM education, such as Carnegie's Opportunity Equation: Citizenship Literacy and Global Economy-Oriented Mathematics and Science Education" put forward that citizens need to have a certain degree of STEAM literacy whether they work in STEAM-related fields or not (Griffiths, 2009) . In addition, the researchers believe that "learning by doing", "constructivism theory", "design thinking in pedagogy", and "6E learning by design model" can be used as theoretical support to promote STEAM education research and practice. Among them, the $6 \mathrm{E}$ learning by design model proposed by the International Technology and Engineering Educators Association (ITEEA) in 2014 is a highly respected curriculum design model in recent years (N B Barry, 2014). This model mainly guides students to understand science through engineering design based on science, technology, and mathematics, thus improving students' scientific literacy. 6E Learning by Design Model includes six links: participation, 
exploration, interpretation, engineering, deepening, and evaluation. A detailed description of the six links is as follows:

(1) Engage: By introducing situations and informing relevant learning tasks in advance, teachers make students connect past and present learning experiences, set up problems to stimulate students' interest in follow-up learning content, and attract students to participate in teaching activities.

(2) Explore: Through the project or problem-based inquiry activities, students have the opportunity to directly participate in the activities and materials, and improve the enthusiasm of students through inquiry science teaching. Throughout the process, students can ask questions, analyze data and think. Develop students' ability to construct their knowledge.

(3) Explain: Students use concepts or principles to explain the process of inquiry, to reflect and refine what they have learned. Through questions, teachers guide students to discuss communication and correct their misconceptions (Tiffany \& Hammer, 2017) so that knowledge and context can be better linked.

(4) Engineer: The teacher introduces students to the relevant concepts and required resources of the design and provides practical application opportunities to the students. Students learn during the inquiry process, perform device-related production and testing, and improve the design.

(5) Enrich: Enrollers promote students' deep understanding of knowledge by introducing new production activities to students and applying them to a wider range of engineering designs.

(6) Evaluate: Teachers use process evaluation to test and evaluate the products produced by students and the whole inquiry learning process, to understand the needs and deficiencies in students' learning, and to promote teachers and students, students and Interaction and communication between students.

There have been many innovations in instructional design (Beauchamp, 1969; Irlbeck, Kays, Jones \& Sims, 2006; Sims \& Jones, 2003; Tennyson, 1999), but most are a variation on the analysis, design, development, implementation, and evaluation (ADDIE) framework developed in the 1950s (Smith \& Ragan, 2004). However, the 6E Learning by Design Model emphasizes both "scientific inquiry" thinking and "engineering design" practice. It requires students as the center and teachers as facilitators to guide students to perceive problems in specific situations and use interdisciplinary knowledge to solve challenging tasks. It's an effective curriculum design model for STEAM education.

\subsection{Theoretical Framework}

Based on the 6E learning by design mode and the characteristics of STEAM education for curriculum design, situation creation is one of the important contents of STEAM curriculum design. Therefore, the curriculum design should not only consider the teaching objectives but also consider the problems that help students to construct their situations. The STEAM physics course based on the 6E learning by design model is designed according to "Engage: the creation and problem discovery of STEAM education and teaching scenarios" - "Explore: exploring the rational solution" - "Explain: through discussion Improve the original plan" - "Engineer: carry out the actual operation of the program" - "Enrich: Enhancing the difficulty of the task" - "Valuate: evaluating communication between groups and groups" are designed to cultivate students' STEAM comprehensive literacy and improve their ability of innovative thinking. The specific process arrangement of the course is shown in Figure 1: 


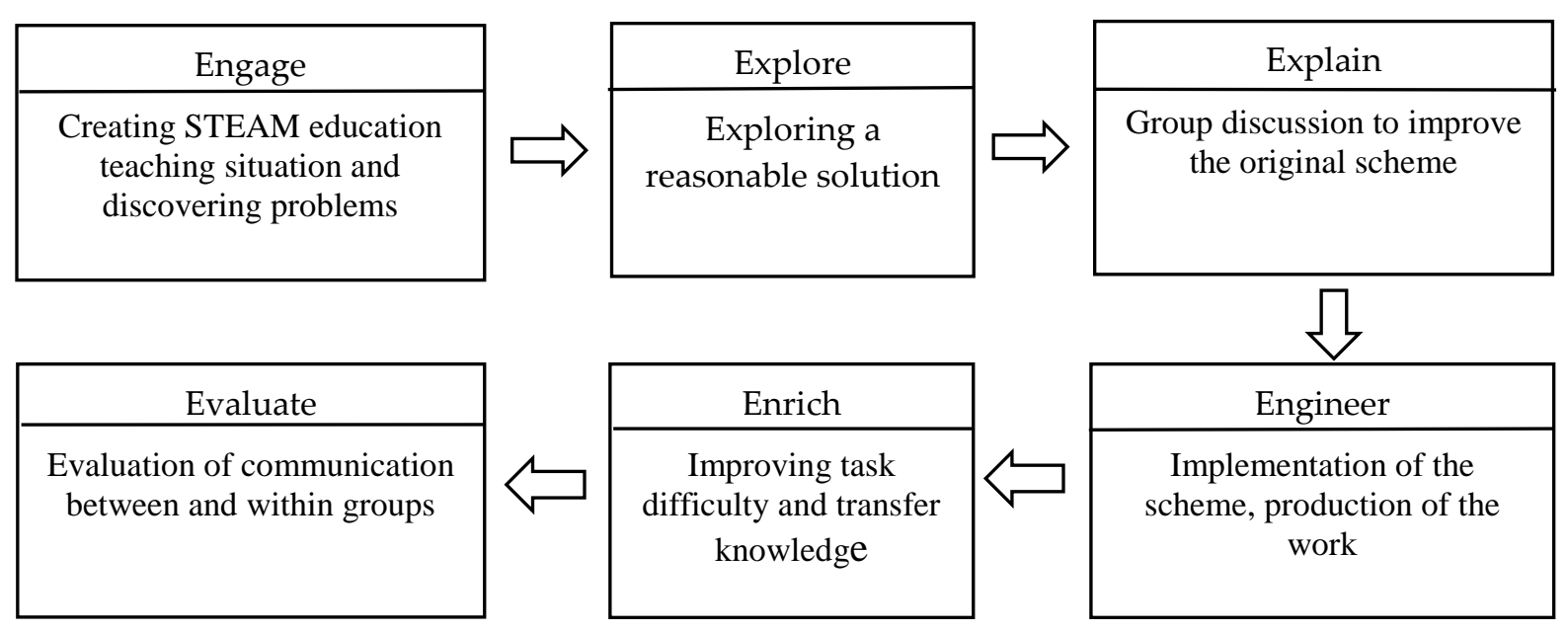

Figure 1. This figure is about STEAM teaching design process based on 6E learning by design model.

\section{STEAM Curriculum Case Introduction}

This case takes the second year students of senior high school as the teaching object, takes physics as the basis, integrates with other disciplines, and takes "manufacturing of hydraulic manipulator" as the project activity theme, on the basis of $6 \mathrm{E}$ learning by design model, combines the characteristics of STEAM education mode to carry out curriculum design. To better design the course teaching activities, it is necessary to clarify the relationship between the knowledge of the hydraulic manipulator, the $6 \mathrm{E}$ design learning model, and the STEAM mode. Figure 2 shows the STEAM knowledge involved in the 6E model teaching process.

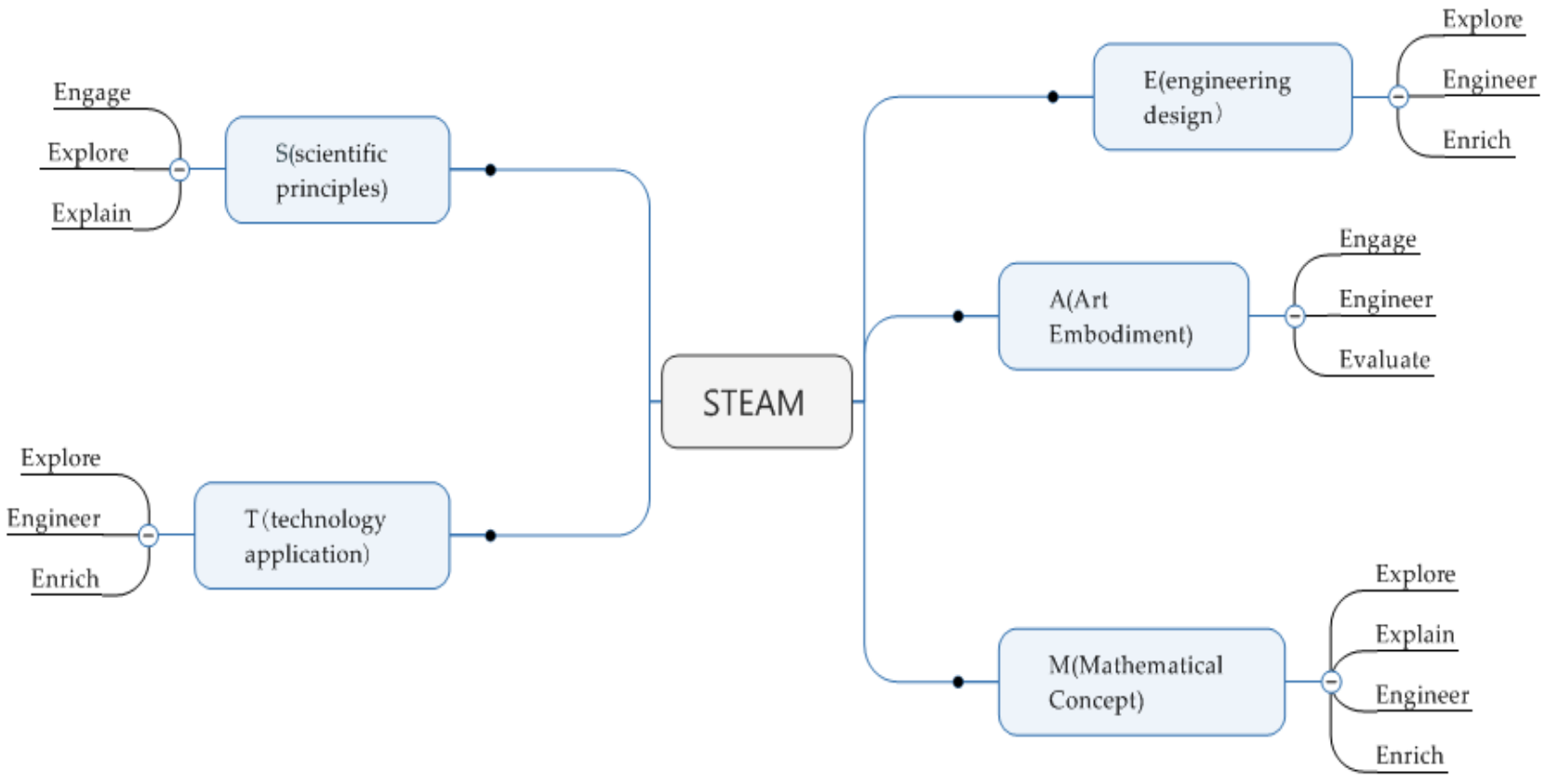

Figure 2. This is a picture that shows the STEAM knowledge involved in the 6E model teaching process. 
The figure below shows the project design sample and its related STEAM knowledge:

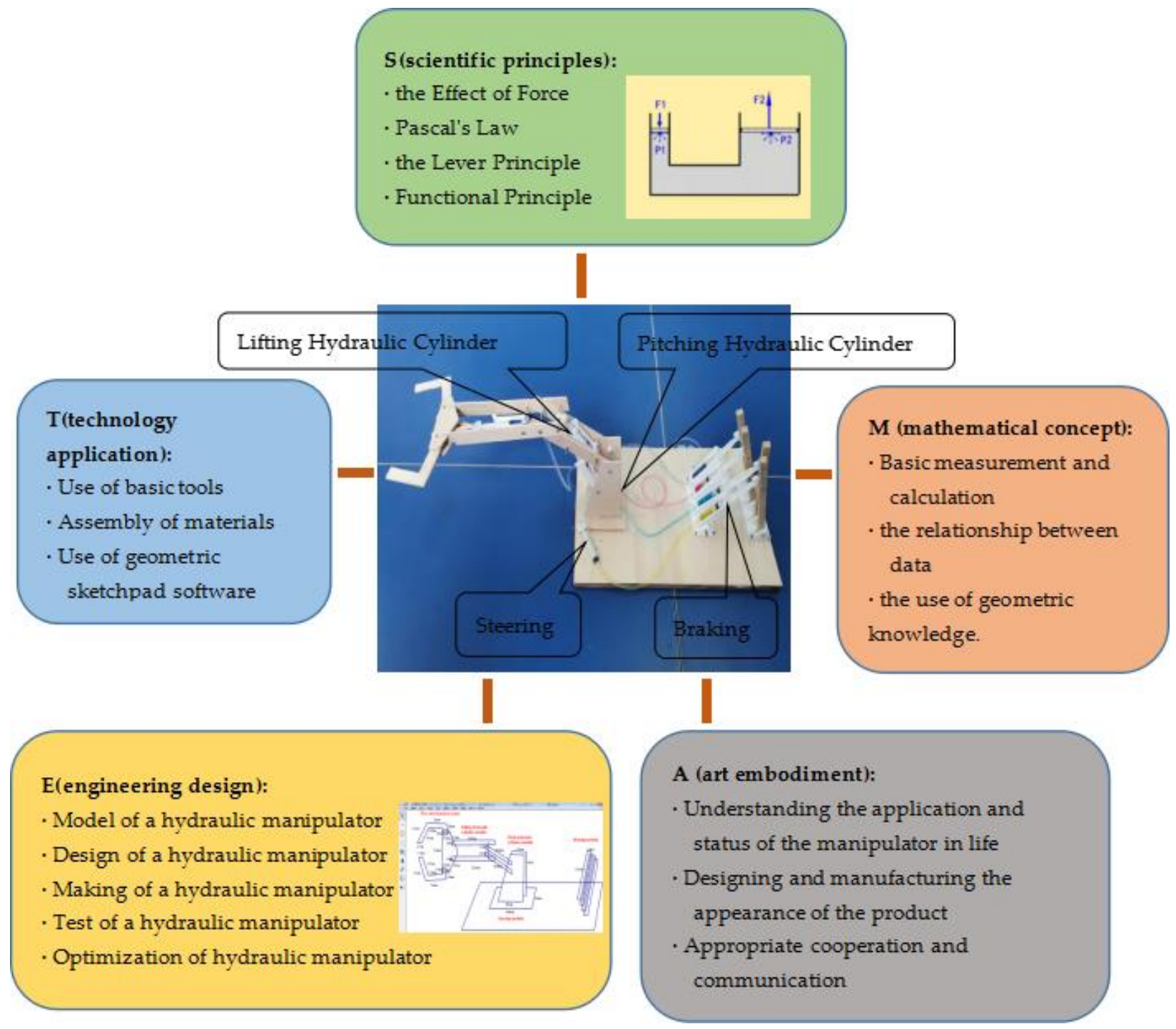

Figure 3. This is a sample of the "hydraulic manipulator" project and the STEAM knowledge involved

\section{STEAM Capability Application Description:}

(1) S: The pressure will change the shape of the liquid. Pascal's law shows that the work done by the liquid pressure in the hydraulic manipulator is converted into kinetic energy. The use of multiple sets of connecting rods between the parts is the use of the principle of the lever to achieve the effect of rotation and labor-saving, so the effect of force, Pascal's law, lever principle and functional principle are all scientific knowledge.

(2) T: Basic tools (the equipment needed for the production: utility knife, electric drill, saw, syringe, claw hammer, screwdriver, hot glue gun, plastic tube, pulley, tape, steel wire, string, ruler, pencil, wooden board) are the auxiliary tools needed for the entire production process. The use of tools belongs to technical 
ability. Assembling materials to examine students' practical operation ability, so it belongs to technical application. The structural drawing of each part of the geometric sketchpad drawing can clarify the student design framework and examine the software usage of students, so it belongs to technical ability.

(3) E: Modeling, making, testing and optimizing hydraulic manipulators using 3D printing technology are essential processes for engineering design.

(4) A: Understanding the application and status of the manipulator in life can improve students' cognitive ability of task products; paying attention to product appearance and production, can promote students' mentality, enhance students' self-confidence and improve students' aesthetic ability; appropriate cooperation and communication can improve students' communication skills.

(5) M: The measurement and calculation of the length, volume, and proportional parameters will use mathematical ability; the relationship between data will be calculated using computational power; the use of geometric knowledge is also mathematical ability.

\subsection{Overview of Teaching Objectives of STEAM Curriculum}

The teaching objectives of the STEAM Curriculum can be described from the perspective of the core literacy of the physics discipline. The learning objectives of this Curriculum can be described as: "Students use the principles of Pascal's law, lever principle and hydraulic transmission to make the hydraulic manipulator, that is, to learn the principle of the hydraulic manipulator through theoretical exploration; to experience the design process of the hydraulic manipulator through experimental inquiry, to deepen the understanding of the hydraulic transmission principle; following the engineering design and technical production procedures, complete the production tasks; through the test to improve the design; through the exploration and group cooperation, students can not only understand the practical use of the hydraulic manipulator in production and life but also improve the students' aesthetic ability and communication skills."

\subsection{STEAM Curriculum Teaching Activities Implementation}

The Curriculum lasts for 7 class hours. Finally, the students' learning effect is tested and evaluated by three ways: learning process record sheet, evaluation scale and small test, in order to guide students to comprehensively apply the subject theory knowledge, cultivate students' knowledge transfer ability and creative thinking.

The STEAM Curriculum based on the 6E model (Patton \& Knochel, 2017) is mainly a "studentcentered" activity Curriculum. After understanding the relationship between hydraulic manipulator knowledge, 6E learning by design model and STEAM mode, the Curriculum mainly requires teachers to implement the STEAM Curriculum according to the teaching design process of Figure 1, gradually guide students to determine the activity tasks, and carry out research and learning in the way of group cooperation. The specific teaching process is as follows:

\subsubsection{Create STEAM Education Teaching Situation and Discovering Problems}

Teachers create scenarios based on real-world case problems, such as video recording of manipulators and car steering gear, guiding students to review hydraulic transmission and other related knowledge, think about the working principle of the manipulators and the automobile steering gear, and their application and status in production and life, so as to put forward the activity tasks of the production of the hydraulic manipulators, using multimedia and other auxiliary means to teach the classroom, in order to stimulate students' desire and motivation.

4.2.2. Explore solutions

REAL 2020, 6(1)

https://doi.org/10.37906/real.2020.5 
According to the task requirements, the teacher guides the students to learn about the modeling knowledge in the form of group cooperation inquiry, consult the design of the physical composition and performance of each part of the "hydraulic manipulators", and learn to use the geometric sketchpad drawing to draw the parts of the product. And to calculate the data parameters, while considering the aesthetics of the product, in order to help students more clearly sort out the steps that the project needs to complete, the teacher needs to guide the group members to discuss and share the product ideas, so as to ensure that the members of each group play a role in task learning, and also cultivate students' selfconfidence and improve students' communication skills.

\subsubsection{Improve the Original Scheme}

In order to improve their respective design schemes, the teachers organize various groups to share the design schemes, encourages each group to show the design idea of the device plane structure schematic diagram of the geometric sketchpad drawing and the related discipline concept knowledge, and also explains the geometric data parameter results of each module in several diagrams. In this part, teachers need to focus on students' understanding of concepts and laws, and expose students' cognitive level and help students to correct their misconceptions through questioning. In order to help each group to compare, exchange and discuss the scheme, so as to improve their own design scheme and promote students to learn more accurately and in-depth.

\subsubsection{Production of Works}

The engineering of STEAM education is reflected in its intentional combination of the content and process of science and mathematics with the content and process of technology and engineering (Sanders, 2009). This process is not only the engineering process in the $6 \mathrm{E}$ learning by design model, but also the key to the "engineering design" and "scientific inquiry" of STEAM education. The teacher first guides the students to reiterate the design process. Each group uses the provided equipment and resources to build the model and print the parts based on the scheme with 3D printer, so as to make the "hydraulic manipulators", and to give appropriate explanations and suggestions for students' doubts in the production process, to promote further improvement and learning. After the production is completed, the students need to perform performance tests on the manufactured products, record the relevant test results, and further optimize the solution according to the test results of the products. Let students experience the engineering design process and help them strengthen their study of mathematics, science and other core subjects on the basis of engineering.

\subsubsection{Transfer Knowledge}

In order to help students expand and extend their knowledge, deepen their understanding of what they have learned, and the ability to transfer learning to new situations, teachers need to set up new scenarios to guide students to upgrade their product offerings by increasing the difficulty of the task. On this basis, the group discussed and analyzed the new issues, and upgraded and improved the original scheme based on the structure of the device and the overall stability. In this part, the group carries out inter group communication for the new scheme, deepen the understanding through interrogation and other ways, so as to help students to experience the engineering design process again.

\subsubsection{Communication and Evaluation}

After the "hydraulic manipulators" production task is completed, the teacher first organizes each group to display the work device, and then evaluates the learning effect of STEAM curriculum of 6E learning by design model. The evaluation process should pay attention to the diversity of the evaluation, and the evaluation form can include Self-evaluation Scale, learning process record sheet, quiz and even the evaluation and summary of the teacher. When evaluating according to this scale, pay attention to 
organizing students to conduct self-evaluation and intra-group evaluation, and the teacher should guide and communicate with the students according to the insufficient performance of the students throughout the inquiry process, and by issuing diagnostic quiz, the students' knowledge learning and goal achievement can be examined.

\section{Results}

Based on the above STEAM curriculum case design, for the first research question, we use the abovementioned STEAM curriculum framework integrated with the $6 \mathrm{E}$ learning by design model to give specific solutions, choose the "manufacturing of hydraulic manipulator" project activity curriculum plan. Unlike the traditional curriculum, the case teaching is no longer dominated by the teaching of single physical subject knowledge. At the same time, the curriculum design elements basically include elements such as teaching goals, teaching processes, teaching evaluation, learning resources, learning objects, class hours, and guiding questions. It can well achieve the purpose of learning the knowledge of "manufacturing of hydraulic manipulator", cultivating students' engineering design ability, aesthetic ability and interdisciplinary comprehensive quality training.

For the second research question, the curriculum evaluation method of this case uses a combination of teaching evaluation, emphasis on multi-subjects, and diverse evaluations, and runs through all links of the teaching process, with specific evaluation content indicators for each link, and the beginning of the teaching objectives. Pay attention to the integration of "teaching, learning, and assessment", and flexibly use a variety of evaluation methods such as activity quizzes and the establishment of students' learning archives. The evaluation scale for presenting and explaining each stage is taken as an example, as shown in Table 1: 
Table 1. Evaluative Scale.

\begin{tabular}{|c|c|}
\hline Teaching Stage & Evaluation Index of STEAM Teaching Content \\
\hline \multirow{3}{*}{$\begin{array}{l}\text { Create STEAM Education } \\
\text { Teaching Situation and } \\
\text { Discovering Problems }\end{array}$} & 1. Concept of Hydraulic Transmission \\
\hline & 2. Composition of the Hydraulic Manipulator \\
\hline & 1. the Hydraulic Manipulator in Life \\
\hline \multirow[t]{4}{*}{ Explore solutions } & 1. Concept and process of modeling \\
\hline & 2. Performance of each part of the hydraulic manipulator \\
\hline & 3. Operation of geometric sketchpad \\
\hline & 4. Calculation of data parameters \\
\hline \multirow[t]{2}{*}{ Improve the Original Scheme } & 1. Formation of design schemes \\
\hline & 2. Cooperation within groups, communication between groups \\
\hline \multirow[t]{3}{*}{ Production of Works } & 1. Construction of the Hydraulic Manipulator \\
\hline & 2. Performance Testing of Products \\
\hline & 3. Beautification of Product Appearance \\
\hline \multirow[t]{2}{*}{ Transfer Knowledge } & 1. Expansion and extension of knowledge \\
\hline & 2. Upgrading and improvement of products \\
\hline
\end{tabular}

The process advocates the combination of teacher evaluation, students' self-evaluation and students' mutual evaluation, take into account the performance and perception of students in the process of task making, give full play to the functional value of evaluation feedback, and promote the comprehensive development of the core literacy of students in physics. This method has changed the disadvantages of adopting the final evaluation only for the purpose of screening and selection in China's traditional education quality test.

For the third research question, the teaching of "Hydraulic Transmission" under the theme of "manufacturing of hydraulic manipulator" in STEAM mode is very different from the traditional "Hydraulic Transmission" teaching. Table 2 compares and explains the four aspects of goal setting, content presentation, teacher-student relationship, learning style, and learning evaluation. 
Table 2. Comparison of STEAM teaching cases and traditional teaching.

\begin{tabular}{|c|c|c|}
\hline Dimension & Traditional Teaching & STEAM Teaching \\
\hline Goal Setting & $\begin{array}{l}\text { The main knowledge of } \\
\text { physics related to hydraulic } \\
\text { transmission, neglect the } \\
\text { training of skills and } \\
\text { methods. }\end{array}$ & $\begin{array}{l}\text { The comprehensive study mainly focuses } \\
\text { on hydraulic transmission knowledge, } \\
\text { hydraulic manipulator engineering design } \\
\text { thinking, production ability, mathematical } \\
\text { calculation ability, and aesthetics, to } \\
\text { cultivate students' physical subject literacy } \\
\text { and development thinking. }\end{array}$ \\
\hline $\begin{array}{c}\text { Content } \\
\text { Presentation }\end{array}$ & $\begin{array}{l}\text { A single discipline lacks real } \\
\text { and continuous contextuality. }\end{array}$ & $\begin{array}{l}\text { Interdisciplinary, contextual knowledge of } \\
\text { hydraulic manipulator runs through the } \\
\text { curriculum. }\end{array}$ \\
\hline $\begin{array}{l}\text { Teacher-Student } \\
\text { Relationship }\end{array}$ & $\begin{array}{l}\text { Teachers are givers of } \\
\text { knowledge, students are } \\
\text { receivers and consumers of } \\
\text { knowledge. }\end{array}$ & $\begin{array}{l}\text { Teachers are the guides of knowledge, and } \\
\text { students are the builders and creators of } \\
\text { knowledge. }\end{array}$ \\
\hline \multirow[t]{4}{*}{ Learning Style } & - Goal driven & - Standard drive \\
\hline & - Textbook driven & - Project or problem driven \\
\hline & - Personal learning & - Research learning \\
\hline & - Dependency resolution & - Solve problems independently \\
\hline \multirow[t]{2}{*}{$\begin{array}{l}\text { Learning } \\
\text { Evaluation }\end{array}$} & $\begin{array}{l}\text { - Focus on results-based } \\
\text { evaluation }\end{array}$ & $\begin{array}{l}\text { - Combining formative and outcomeive } \\
\text { evaluation }\end{array}$ \\
\hline & $\begin{array}{l}\text { - Evaluate students with } \\
\text { exams and quizzes }\end{array}$ & $\begin{array}{l}\text { - Evaluate students based on student } \\
\text { performance and product completion }\end{array}$ \\
\hline
\end{tabular}

\section{Conclusions}

STEAM's concept of "interdisciplinary" education is in line with the requirements of physical curriculum reform and the new direction of development in China. It is not only an integrated education of disciplines, but also a trend of curriculum design, and also an innovation of teaching methods. The $6 \mathrm{E}$ learning by design model enables students to carry out "learning by doing" education, which not only can cultivate students' ability of "engineering design" and "scientific inquiry", but also cultivate students' comprehensive quality and innovative ability. The "manufacturing of hydraulic manipulator" curriculum in STEAM mode has the following characteristics:

\subsection{Curriculum Objectives and Tasks are Clear}

Curriculum objectives are formulated in accordance with the requirements of the four-dimensional goal of core literacy for students in physics in the Standards for General Senior High School Physics Curriculum (2017 Edition). For example, students' physical concepts are designed to learn the principles of 
hydraulic manipulators through theoretical inquiry; scientific thinking is designed to deepen the understanding of hydraulic transmission principles and design schemes through the design process; scientific inquiry design is based on engineering design and technical production Procedures, complete production tasks; through inquiry and teamwork, scientific attitudes and responsibilities are designed to understand the practical use of robotic arms in production and life, and improve aesthetic abilities and communication skills. Based on this, the task goal of the "manufacturing of hydraulic manipulator" is clearer. It complies with the curriculum standards of China. It helps students understand the interrelationships between physics, society, and technology, and initially forms basic inquiry operation skills to keep students curious about physical phenomena in life. Strengthen the desire for inquiry into physical phenomena in nature.

\subsection{The Curriculum is Closely Connected with Life}

STEAM education is a design idea based on constructivist theory, emphasizing the cultivation of students' self-construction ability and the ability to connect knowledge with social life. Therefore, in the course of learning, it is the difference between stem course and traditional course to guide students to connect existing life experience and knowledge, stimulate students' learning motivation, and actively construct knowledge for learning. For example, in the case of the "manufacturing of hydraulic manipulator" in this case, using the working video of common mechanical arm and automobile steering gear in life, students' curiosity and desire to explore are aroused. Through the design of the plan and experimental exploration to make the task of the hydraulic manipulator, students can experience the process of inquiry by scientists and learn to summarize the laws of hydraulic transmission to solve the actual working problem of the hydraulic manipulator.

\subsection{E Learning by Design Model on Experimental Exploration and Engineering Design}

The $6 \mathrm{E}$ learning by design model on this study case mainly uses classroom teaching conducted by scientific inquiry and engineering design mode. The teaching process of the entire "manufacturing of hydraulic manipulator" course is designed based on the links of this mode. Compared with the traditional teaching mode, this teaching case is student-centered, starting from the problem of life situation, inspiring students' curiosity, causing students to think about hydraulic transmission problems, and then determining and exploring the task of "manufacturing of hydraulic manipulator" Until the students are guided to complete the production of tasks, the entire processology guides students to flexibly carry out selfconstruction of knowledge, progressively layer by layer, and cultivates students' scientific ability, engineering ability, mathematical ability, and aesthetic ability, which is in line with the ideas of STEAM education and Requirements for comprehensive talent training. The final evaluation link also adopted a combination of multi-subjects and diversification, which took into account the performance and perception of students in the task production process, and promoted the development of the core literacy of students in physics.

Therefore, curriculum development based on STEAM educational concept has important guiding significance for the reform of physics curriculum in China. When setting up the STEAM curriculum, it is necessary to emphasize not only teachers should guide students to solve problems based on situational perception and interdisciplinary knowledge, but also focus on student-centered and teacher-guided project design and production in the form of group cooperation and inquiry. 
Funding: This research was funded by Humanities and Social Sciences project of the Ministry of Education of China, grant number 18YJC880094 and Educational Science Planning Project of Hubei Province, grant number 2019GB024.

Acknowledgments: Firstly, the author would like to thank the teachers and students of Senior High School in Jingzhou City for their support and cooperation in this physics curriculum. Secondly, thank the professor Xie for her guidance and comments on the author' s research paper

Conflicts of Interest: The authors declare no conflict of interest.

\section{References:}

Anderson, C. W., de los Santos, E. X., Bodbyl, S., Covitt, B. A., Edwards, K. D., Hancock, J. B., ... \& Welch, M. M. (2018). Designing educational systems to support enactment of the Next Generation Science Standards. Journal of Research in Science Teaching, 55(7), 1026-1052.

Anggraini, P., \& Sani, R. A. (2015). The effect of scientific inquiry learning model and creative thinking ability on science process skills of student. Jurnal Pendidikan Fisika, 4(2), 47-54.

Burke, Barry N. (2014). The iteea 6e learning by design [tm] model: maximizing informed design and inquiry in the integrative stem classroom. Technology \& Engineering Teacher, 73.

Bybee, R. W. (2013). The case for STEM education: Challenges and opportunities. NSTA press.

Beauchamp, G. A. (1969). Curriculum process by D. K. Wheeler. The Educational Forum, 34(1), 144- 145.

Connor, A., Karmokar, S., \& Whittington, C. (2015). From STEM to STEAM: Strategies for enhancing engineering \& technology education. International Journal of Engineering Pedagogy, 5(2), 37-47.

Carnegie Corporation of New York - IAS Commission. (2009). The opportunity equation: Transforming mathematics and science education for citizenship and the global economy.

Erman, E., Wasis, W., Susantini, E., \& Azizah, U. (2018, December). Scientific Thinking Skills: Why Junior High School Science Teachers Cannot Use Discovery and Inquiry Models in Classroom. In International Conference on Science and Technology (ICST 2018). Atlantis Press.

Havice, W. (2009). The power and promise of a STEM education: Thriving in a complex technological world. The overlooked STEM imperatives: Technology and engineering, 10-17.

Hill, R. A. (2013). Narrative nonfiction for STEM (science, technology, engineering, and math) reading: One option for Common Core literacy. Teacher Librarian, 40(3), 31.

Honey, M., Pearson, G., \& Schweingruber, H. A. (Eds.). (2014). STEM integration in K-12 education: Status, prospects, and an agenda for research (Vol. 500). Washington, DC: National Academies Press.

Irlbeck, S., Kays, E., Jones, D., \& Sims, R. (2006). The phoenix rising: Emergent models of instructional design. Distance Education, 27(2), 171-185. 
Patton, R. M., \& Knochel, A. D. (2017). Meaningful makers: Stuff, sharing, and connection in STEAM curriculum. Art Education, 70(1), 36-43.

Richter, D. M., \& Paretti, M. C. (2009). Identifying barriers to and outcomes of interdisciplinarity in the engineering classroom. European Journal of Engineering Education, 34(1), 29-45.

Sikorski, T. R., \& Hammer, D. (2017). Looking for coherence in science curriculum. Science Education, 101(6), 929-943.

Sanders, M. (2009). STEM, STEM education, STEMmania. The Technology Teacher, 68(4), 20-26.

Sims, R., \& Jones, D. (2003). Where practice informs theory: Reshaping instructional design for academic communities of practice in online teaching and learning. Information Technology, Education and Society, 4(1), online-online.

Smith, P. L., \& Ragan, T. J. (2004). Instructional design. John Wiley \& Sons.

Toulmin, C. N., \& Groome, M. (2007). Building a science, technology, engineering, and math agenda. National Governors Association.

Tennyson, R. D. (1999). Instructional development and ISD4 methodology. Performance Improvement, 38(6), 19-27.

USNews( 2014) . Derived from: http: / /www.usnews.com/news/articles/2014/02 /04 /5 - more - unive - rsities - will - create - stem - teacher - training - programs

Yakman, G. (2008, February). STEAM education: An overview of creating a model of integrative education. In Pupils' Attitudes Towards Technology (PATT-19) Conference: Research on Technology, Innovation, Design \& Engineering Teaching, Salt Lake City, Utah, USA.

Yakman, G., \& Lee, H. (2012). Exploring the exemplary STEAM education in the US as a practical educational framework for Korea. Journal of the Korean Association for Science Education, 32(6), 1072-1086. 